\title{
MODALIDADE E FOCO: UMA ANÁLISE BASEADA EM DADOS DE CORPUS
}

\author{
Amália Mendes ${ }^{1}$
}

\begin{abstract}
Resumo
Apresenta-se neste artigo uma análise da interação entre os conceitos de modalidade e de foco em contextos com o advérbio focalizador exclusivo só e um verbo semi-auxiliar modal (poder, dever ou ter (de)) ou ainda a estrutura predicativa ser capaz de. Interessa-nos observar de que forma o advérbio exclusivo, com efeitos sobre a estrutura informacional, pode interagir com o significado modal de base do contexto e ainda aduzir eventuais valores pragmáticos.

O trabalho enquadra-se na Linguística de Corpus, assumindo a necessidade de basear a análise em dados de corpora, isto é, em contextos não construídos. Para esse efeito, recorreu-se ao Corpus de Referência do Português Contemporâneo, um corpus que abrange um conjunto diversificado de géneros textuais. Os contextos foram selecionados de forma aleatória sobre a subparte de português europeu. A análise dos dados mostra de que forma contextos com uso epistémico de possibilidade do verbo poder são interpretados como tendo uma leitura de necessidade após a restrição sobre o conjunto de alternativas realizada pelo advérbio focalizador. Os dados apontam pistas importantes no que diz respeito às propriedades que determinam a leitura de necessidade, sendo aqui fundamental a natureza do foco do advérbio, o tempo do predicado e a sua natureza aspetual. O advérbio tem ainda, em muitos contextos, quer um valor mirativo, identificando a alternativa como mais fraca do que o esperado, quer um valor enfático de reforço da alternativa apresentada.
\end{abstract}

Palavras-chave: Modalidade, Foco, Advérbios focalizadores exclusivos, Linguística de Corpus

\begin{abstract}
We present in this paper an analysis of the interaction between the concepts of modality and focus in contexts with the exclusive adverb só 'only' and a modal semi-auxiliary (poder 'may/can', dever 'should/must', ter de 'have to') or the adjective in the construction ser capaz de 'be able to'). Our goal is to observe in which way the exclusive adverb, which operates on the information structure level, may interact with the modal meaning of the sentence and in some cases produce pragmatic values.

Our framework is Corpus Linguistics, as we assume that we should base our findings on authentic and nonconstructed data. We selected a random set of equal contexts from the European Portuguese subset of the Reference Corpus of Contemporary Portuguese, a corpus that covers a wide range of genres. Our analysis explores contexts where the epistemic possibility value of the verb poder is reinterpreted as modal necessity after the restriction of alternatives operated by the exclusive adverb. Data points to a set of crucial properties for the necessity meaning to be available, such as the type of focus of the adverb, the tense of the main predicate verb and its aspectual profile. The exclusive adverb may furthermore adduce pragmatic values to the context, either a mirative value, by identifying the alternative as weaker than expected, or an emphatic value, by reinforcing a single alternative.
\end{abstract}

Keywords: Modality, Focus, Exclusive adverbs, Corpus Linguistics

\section{Introdução}

A modalidade é caracterizada como a expressão da atitude ou opinião do sujeito em relação à proposição (LYONS, 1977) e, ainda, como um conceito que se prende com "situações alternativas" (OLIVEIRA, 1993). Em contextos naturais extraídos de corpora verifica-se uma frequente interação entre diferentes elementos que contribuem para a leitura modal do enunciado, como verbos semi-auxiliares modais, adjetivos, advérbios e ainda o tempo verbal. Para além de elementos com significado modal, existem outros fenómenos linguísticos que afetam a modalidade, como o caso já bastante estudado da negação (MORANTE; SPORLEDER, 2012. OLIVEIRA, 1993). Este artigo foca o caso específico da

\footnotetext{
${ }^{1}$ Centro de Linguística da Universidade de Lisboa, amalia.mendes@clul.ul.pt. Trabalho financiado parcialmente
} 
interação entre elementos modais e o advérbio só, considerado um advérbio focalizador exclusivo (BEAVER; CLARK, 2008. RAPOSO, 2013). Este advérbio, juntamente com outros advérbios focalizadores exclusivos, caracteriza-se por selecionar determinadas entidades de um conjunto mais vasto. Essas entidades, que constituem um constituinte proeminente em termos informacionais, são designadas como o foco do advérbio. As entidades excluídas dessa operação formam um conjunto complementar (RAPOSO, 2013) ou background (BEAVER; CLARK, 2008).

O estudo aqui apresentado insere-se nos trabalhos realizados no âmbito da elaboração de um esquema de anotação da modalidade para o português (HENDRICKX; MENDES; SALGUEIRO, 2012a) aplicado sobre um corpus escrito de cerca de 160.000 palavras (HENDRICKX et al., 2012b), extraído do Corpus de Referência do Português Contemporâneo (CRPC), um corpus escrito e oral com cerca de 312 milhões de palavras de diferentes variedades nacionais do português e cobrindo um vasto leque de tipos textuais (GÉNÉREUX; HENDRICKX; MENDES, 2012). Um esquema de anotação da modalidade para textos orais de português do Brasil que partilha características importantes com o trabalho sobre o português europeu foi desenvolvido em Ávila (2014), havendo ainda uma proposta de unificação dos dois esquemas (ÁVILA; MENDES, 2015). O trabalho de anotação tem o mérito de chamar a atenção para a complexidade dos fenómenos em análise e, no caso da anotação da modalidade, apontou para diversos elementos que interagem com o valor modal global do enunciado, entre os quais o do advérbio exclusivo só. Interessa-nos aqui explorar dados que foram já apontados de forma preliminar na anotação do corpus (MENDES et al., 2013) e analisar as implicações semânticas e pragmáticas da coocorrência de verbos semi-auxiliares modais com o advérbio exclusivo só.

Para este efeito, baseamos a nossa análise em contextos em que coocorrem o advérbio só e um dos verbos semi-auxiliares modais: dever, poder, ter (de), e ainda a estrutura predicativa ser capaz de. Baseamos a nossa análise em contextos extraídos do CRPC na plataforma online CQPweb ${ }^{2}$. Restringimos a nossa pesquisa ao subcorpus de português europeu, com 289 milhões de palavras, e procurámos contextos com a forma só seguida do lema verbal ou adjetival, contíguos ou separados por 1 a 5 palavras. Dado o número elevado de contextos, seleccionámos para análise 100 ocorrências de cada lema, ordenadas aleatoriamente.

\footnotetext{
${ }^{2}$ http://alfclul.clul.ul.pt/CQPweb/crpcweb23/index.php
} 


\section{Os conceitos de modalidade e foco}

A literatura sobre a modalidade é extensa e as tipologias propostas são variadas, sendo que todas apresentam um valor modal estável, o valor epistémico, central nos estudos sobre modalidade (PALMER, 1986; PORTNER, 2009; BYBEE; PERKINS; PAGLIUCA, 1994). Neste trabalho, seguimos a tipologia quadripartida apresentada por VAN DER AUWERA; PLUNGIAN (1998), que se organiza em torno de duas dimensões modais fundamentais, a possibilidade e a necessidade. Os valores considerados são o epistémico (crença e valor de verdade), deôntico (obrigação e permissão), interno ao participante (capacidade e necessidade) e externo ao participante (necessidade e possibilidade que resultam de fatores externos).

Os estudos linguísticos sobre modalidade têm sobretudo incidido, nas línguas europeias, sobre os verbos semi-auxiliares modais, embora verbos plenos e outras classes de palavras, como os adjetivos, os advérbios e alguns verbos plenos também veiculem valores modais e sejam objeto de atenção (HOYE, 1997. OLIVEIRA; MENDES, 2013). Neste trabalho, iremos centrar a nossa análise nos contextos com verbos semi-auxiliares modais e ainda na estrutura predicativa ser capaz de. Os verbos semi-auxiliares modais sugerem também questões de natureza sintática, como, por exemplo, a preferência em português do Brasil por estruturas com projeção de um sujeito sobre construções impessoais, ao contrário da variedade europeia do português (DUARTE, 2012).

Por sua vez, o conceito de foco é tomado como "a means to give prominence to meaning-bearing elements in an expression.” (KRIFKA, 1995:240), veiculando informação nova, contraste ou um conjunto de alternativas (ROOTH, 1992). Para a língua inglesa, os estudos sobre o advérbio focalizador only realçam a sua natureza de partícula sensível ao foco, que remete para a estrutura informacional da frase (ALONI; BEAVER; CLARK, 1999), sendo que "the position of focal accent identifies the constituent associated with only" (DRYER, 1994:2). O significado de only consiste em asserir que, no conjunto de alternativas, não existe nenhuma proposição verdadeira para além da que é expressa (VON FINTEL, 1994). O estudo de Moreira (2005) sobre marcadores enunciativos em português inclui o advérbio só no conjunto desses marcadores e considera que esse "põe em relação um termo selecionado $y$ com o conjunto $Y$ de um ou mais termos oponíveis ou alternativos a $y$. A não selecção de outro termo que não $y$ estabelece a dimensão negativa da construção." (MOREIRA, 2005, p.46). As construções com partículas exclusivas envolvem uma componente positiva e outra negativa: a positiva é designada como prejacente e, na frase (1) 
corresponde a 'a paralisação é capaz de provocar a reação dos utentes com a ida para o trabalho dificultada' enquanto a negativa é designada como universal e corresponde na mesma frase a 'a paralisação não é capaz de provocar a reação dos restantes utentes'.

(...) a paralisação dos Transportes Sul do Tejo, das 15 horas de hoje até às 3 horas de amanhã, só será capaz de provocar a reacção dos utentes com a ida para o trabalho dificultada. (J60772) $)^{3}$

Este tipo de advérbios pode igualmente avaliar a alternativa como não sendo tão forte quanto tipicamente seria de esperar, uma função designada como mirativa (BEAVER; CLARK, 2008), isto é, em que há codificação gramatical de informação inesperada:

Exclusives have a peculiar duality that seems almost paradoxical. Positive and negative. At one and the same time, they can add emphasis, by saying that some alternative is the strongest that is true, and they can downtone, by underlining the fact that the alternative is not the strongest that in principle might have been the case. We suggest that while exclusives have truth conditional effects, their function is partly MIRATIVE, to say that the true answer to the Current Question is surprisingly weak, and control the flow of discourse by resetting expectations about that answer. (BEAVER; CLARK, 2008, p. 250)

Assim, Moreira (2005) realça, em relação à frase (2), a existência de duas interpretações, sendo uma delas "minimal" parafraseável por "é pouco o que ele quer" (Moreira 2005: 41). Nessa leitura, não são verdadeiramente considerados outras eventuais alternativas para além da que é enunciada.

Ele só quer ir ao cinema (MOREIRA, 2005, p.41)

\section{Análise dos dados}

Os verbos e adjectivo modais em consideração neste trabalho podem ter diferentes leituras em contexto, que iremos rever brevemente para podermos avaliar a sua interpretação junto com o advérbio focalizador exclusivo.

O verbo poder admite a totalidade das leituras modais indicadas na secção anterior: uma leitura epistémica, em que o sujeito ou outro interveniente no universo do discurso avalia o valor de verdade da proposição; uma leitura deôntica de permissão e uma leitura de possibilidade externa ao participante; e ainda uma leitura em que se refere uma capacidade interna ao participante. Note-se que muitos contextos têm mais do que uma leitura possível de entre as 4 referidas acima. Os verbos dever e ter $(d e)$ têm leitura deôntica de obrigação e de

\footnotetext{
${ }^{3}$ Fornecem-se referências sobre a fonte dos exemplos no final do artigo.
} 
necessidade externa ao participante; e ainda epistémica, avaliando o grau de probabilidade do valor de verdade da proposição. Finalmente, a expressão ser capaz de tem tipicamente valor de capacidade interna ao participante, embora também ocorra com valor epistémico de possibilidade.

Os advérbios focalizadores exclusivos podem atribuir proeminência a diferentes constituintes na frase ou foco. Enquanto no exemplo (2) só tem escopo sobre o verbo e seus complementos (ir ao cinema), em (3a) tem escopo sobre o sujeito, em (3b) sobre o adjunto temporal e em (3c) sobre a oração condicional. Note-se que o advérbio só poderia ocorrer imediatamente antes do adjunto temporal e manter a mesma leitura que em (3b) (só numa primeira fase do tratamento).

(3) a. Só tu és capaz de resumir depressa e bem. (L0979)

b. Há quem defenda que os medicamentos só devem ser usados numa primeira fase do tratamento. (J99704)

c. Mas só a posso vestir se os meus sapatos pretos, aqueles ingleses, já tiverem vindo do sapateiro e se estiverem engraxados convenientemente. (R1641)

Como mostram os exemplos acima, a partícula exclusiva não é necessariamente contígua ao constituinte ou elemento que constitui o foco. Uma análise de uma amostragem de contextos do advérbio só com verbos semi-auxiliares modais aponta para o facto de, na maioria dos casos, o advérbio ter como foco um constituinte como o sujeito, os complementos ou adjuntos. O foco do advérbio exclusivo pode ser ambíguo em certos contextos, embora haja na maioria dos casos uma interpretação preferencial. Veja-se o exemplo (4) que pode ser interpretado como 'a única coisa que sou capaz de fazer é colocar uma questão metafísica' ou 'a única questão que sou capaz de colocar é de ordem metafísica'.

$$
\text { (...) só sou capaz de colocar ao Sr. Ministro uma questão metafísica (...). (DAR) }
$$

\section{Poder}

Como foi referido, o verbo poder pode ter várias leituras modais de acordo com o contexto. Apresenta-se na Tabela 1 informação sobre os valores modais que ocorrem com este verbo na nossa amostragem, a sua frequência e percentagem, e informação de frequência sobre o tipo de foco do advérbio: o predicado ou um constituinte mais delimitado. 


\begin{tabular}{|c|c|c|c|c|c|c|}
\hline \multicolumn{7}{|l|}{ poder } \\
\hline \multirow{2}{*}{\multicolumn{3}{|c|}{ valor modal }} & \multicolumn{4}{|c|}{ foco } \\
\hline & & & predicado & & constituinte & \\
\hline & freq & $\%$ & freq & $\%$ & freq & $\%$ \\
\hline epistémico & 56 & $56 \%$ & 15 & $27 \%$ & 41 & $73 \%$ \\
\hline deôntico & 29 & $29 \%$ & 0 & $0 \%$ & 29 & $100 \%$ \\
\hline epistémico/capacidade & 9 & $9 \%$ & 2 & $22 \%$ & 7 & $78 \%$ \\
\hline capacidade & 5 & $5 \%$ & 0 & $0 \%$ & 5 & $100 \%$ \\
\hline
\end{tabular}

Tabela 1: Verbo poder: valores modais e natureza do foco

Os dados da Tabela 1 mostram que o valor epistémico é dominante nas ocorrências do corpus e que o foco do advérbio é maioritariamente um constituinte mais delimitado do que a totalidade do predicado, como o sujeito em (5a) ou o agente da passiva em (5b). O foco no agente da passiva é aliás uma ocorrência frequente nos contextos com poder, com 27 ocorrências em 100 contextos.

(5) a. Só uma dedicação muitíssimo grande poderia levar a que este hospital tivesse uma actividade das maiores do País (...) (J69887)

b. Os pedidos de assistência financeira, ressalvada a representação legal, só podem ser formulados: c) Pelos proprietários de pleno domínio; b) (...) (DAR)

- Leitura de capacidade interna ao participante e leitura deôntica

O valor de capacidade interna ao participante ocorre apenas 5 vezes com o verbo poder na amostragem considerada (cf. (6a)). Há ainda 9 contextos que são ambíguos entre uma interpretação epistémica de possibilidade e uma interpretação de capacidade interna ao participante: por exemplo, em (6b) é possível a leitura 'só depois disso teremos capacidade para fazer mais comentários' ou 'só depois disso será possível fazer mais comentários'. Apenas entre este subconjunto de contextos ambíguos com uma leitura epistémica é possível encontrar 2 casos de foco no predicado, como se ilustra em (6c), embora mesmo neste caso nos pareça possível uma interpretação de foco sobre o objeto direto 'só podemos reafirmar isso e não outra coisa'. O foco no predicado está fortemente associado ao valor epistémico, pois os 17 casos encontrados com poder têm leitura epistémica ou apresentam ambiguidade entre a leitura epistémica e de capacidade interna.

(6) a. Só um choque fiscal pode reanimar a economia. (DAR)

b. «Fomos informados de que 21 pessoas de Timor estão na nossa Embaixada em Jacarta, mas os nossos funcionários estão ainda a tentar saber exactamente quais são as suas intenções», referiu a fonte do Ministério dos Negócios Estrangeiros do Japão. 
«Só depois disso é que poderemos fazer mais comentários», disse a fonte contactada telefonicamente em Tóquio a partir de Macau. (J9736)

c. Sobre o projecto, em si mesmo, só podemos reafirmar o que já afirmámos antes, ou seja, este vosso projecto é uma proposta absurda, cheia de equívocos (...). (DAR)

Quanto à leitura deôntica, uma vez que nalguns casos existe ambiguidade entre uma leitura deôntica de permissão e uma leitura de possibilidade externa aos participantes, consideramos as duas categorias debaixo da etiqueta deôntico, que perfaz 29 ocorrências no corpus. Em todas elas, o foco do advérbio só é um constituinte (o sujeito, o agente da passiva, o adjunto temporal ou uma oração relativa).

\section{- Leitura epistémica}

A leitura epistémica ocorre em 56 contextos do corpus analisado. Nestes contextos, o advérbio focalizador exclusivo, em conjunto com determinadas propriedades da frase, pode contribuir para uma alteração da leitura modal ou ainda para efeitos pragmáticos.

Nos contextos em que o verbo poder tem leitura epistémica de possibilidade, o advérbio só pode restringir o conjunto de alternativas à que foi apresentada na frase (x e só x), como se exemplifica em (7).

(7) a. Quando as canções são criteriosamente escolhidas pelo próprio, de um reportório tão rico como este, o resultado só podia ser positivo. (noCOD_1062920)

b. (...) que permite a qualquer entidade, funcionário ou indivíduo participar ao Conselho Superior Judiciário factos referentes à má administração da justiça ou ao comportamento dos magistrados e funcionários judiciais. É regra estimuladora da moralidade que só pode ser louvada. (DAR)

Ao restringir o conjunto de situações a uma única, o advérbio produz uma leitura global da frase como expressando valor de necessidade epistémica, o que ocorre em 17 ocorrências na amostra. Assim, o significado das frases em (7) pode ser considerado equivalente ao das frases adaptadas em (8) com o verbo modal com valor de necessidade ter de. As frases declarativas equivalentes em (9) têm um valor assertivo, enquanto (7a) assere uma possibilidade de entre um conjunto de alternativas. Nesse sentido, Moreira (2005), que aponta o valor de necessidade nestes contextos, considera que em frases como (7) só é o marcador de uma operação modal de exaustividade e pode ser considerado um marcador de sobremodalização. 
(8) a. (...) o resultado tinha de ser positivo.

b. É regra estimuladora da moralidade que tem de ser louvada.

(9) a. (...) o resultado é positivo.

b. É regra estimuladora da moralidade que é louvada.

A leitura de necessidade não surge em todos os contextos epistémicos de só com o verbo poder. Dois padrões sobressaem na nossa amostragem: por um lado, a leitura de necessidade está associada na amostragem a uma combinação de advérbio só + poder + predicado estativo (perfil aspetual básico ou derivado), como ilustram os exemplos (7). Por outro lado, o foco do advérbio parece desempenhar uma função importante para a leitura de necessidade. De facto, essa leitura surge predominantemente (frequência 11), em contextos em que o foco do advérbio é o predicado. Para ilustrar o contraste, compare-se, por exemplo, a frase extraída do corpus em (10a) com a sua correspondente adaptada em (10b). Na primeira, o foco do advérbio é o adjunto temporal e a leitura global da frase continua a ser de possibilidade epistémica: estabelece-se uma possibilidade (a deputada ter razão) e sobre ela aplica-se uma condição (quando acertar nalguma previsão). Na segunda, o advérbio tem escopo sobre todo o sintagma verbal: estabelece-se uma possibilidade (a deputada ter razão) e o advérbio restringe as alternativas à possibilidade que é expressa, pelo que a leitura global é de necessidade (a deputada tem de ter razão).

(10) a. Ora, a Sr. ${ }^{a}$ Deputada MFL só pode ter razão quando acertar nalguma previsão. (DAR)

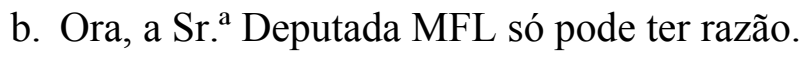

(11) Por isso, este despacho só pode pretender criticar e condenar o Primeiro-Ministro! (DAR)

A leitura de necessidade pode ocorrer em contextos em que o foco do advérbio é o objecto direto ou o predicativo do sujeito. No entanto, estes são contextos em que esses constituintes integram ou são constituídos pelo numeral um, que restringe as alternativas a uma só, tal como quando o foco incide sobre todo o predicado. Ilustram-se estes contextos com as frases (12):

(12) a. A corrupção e a podridão no poder só podem ter um efeito: arbitrariedade, impunidade e crime. (DAR)

b. (...) depois de ouvirmos o seu discurso, a constatação só pode ser uma: a presidência portuguesa foi um enorme êxito. (DAR) 
Quando o verbo poder ocorre junto de verbo eventivo, o foco do advérbio só é um adjunto nos contextos analisados (cf. (13)). Estas frases não ganham leitura de necessidade: por exemplo, em (13a), os notários podem vir a passar habilitação ou não, não têm de o fazer, e sobre essa possibilidade existe uma condição. O tipo de foco é, portanto, um fator determinante para a interpretação, como acontecia com os exemplos com predicados estativos em (7).

(13) a. Os notários só poderão passar certidões de qualquer habilitação depois de decorridos trinta dias sobre a data da publicação do anúncio. (DAR)

b. Segundo o diploma, os pilotos poderão fazer três voos nocturnos consecutivos, quando só podiam fazer um por semana. (J44918)

c. Em seu entender, "é do mais elementar bom senso saber-se que só se pode executar responsavelmente um projecto quando está garantido o financiamento" (noCOD_1062203)

Repare-se que numa frase construída como (14a), com o predicado eventivo no infinitivo pretérito (ter ido), o verbo poder tem leitura epistémica e a frase ganha valor de necessidade, como nas frases (7). Neste caso existe apenas a leitura em que o João terá de facto desempenhado uma atividade, sendo que apenas uma das alternativas é válida (tem de ter ido à praia). A frase (14b), com o verbo no infinitivo presente, tem pelo contrário leitura deôntica de permissão (ou de capacidade) e o advérbio restringe as alternativas a uma só (isto é, ir a praia é a única coisa que o João tem permissão para fazer). Nesta leitura, não surge o valor de necessidade: o João só tem permissão para ir à praia, mas não tem de o fazer. $\mathrm{O}$ tempo verbal é portanto um fator determinante para a leitura modal em contextos de predicados eventivos.

(14) a. O João só pode ter ido à praia.

b. O João só pode ir à praia.

Alguns contextos com leitura epistémica de poder não tomam verdadeiramente em conta uma pluralidade de alternativas das quais se salientaria uma única, tendo antes um valor enfático sobre a situação apresentada, como nas frases (15).

(15) a. (...) creio que todos aqueles que, ao longo de 20 anos, tal como o Partido Comunista Português, sempre defenderam as regiões administrativas, só poderiam congratular-se com o facto de o PS ter apresentado dois projectos de lei que 
lamentamos ainda não ter tido oportunidade de analisar mas que faremos com todo o cuidado possível. (DAR)

b. Por isso, este despacho só pode pretender criticar e condenar o Primeiro-Ministro! (DAR)

Nalguns contextos com o verbo poder e advérbio só, este não pode ser omitido na frase sem alterar profundamente o seu valor pragmático. Assim, ao contrário dos contextos discutidos acima, a frase (16) sem o advérbio focalizador exclusivo não é adequada à situação de comunicação (\#Os estudantes comentaram à Lusa a decisão do procurador: «pode ser uma partida de Carnaval».). Note-se que em (16) os estudantes não estão de facto a considerar que a situação é uma partida de Carnaval, mas sim que a situação é de tal forma inusual ou caricata que não pode ser levada a sério. Não se trata, pois, de uma avaliação de condição de verdade.

(16) Os estudantes comentaram à Lusa a decisão do procurador: «Só pode ser uma partida de Carnaval». (J47486)

Esta interpretação prende-se com um uso que não ocorreu na amostragem em consideração nesta análise e no qual, em situação de interacção, os falantes usam a sequência formada pelo advérbio só e pelo verbo pode (só pode) com valor de assentimento em resposta a uma pergunta ou afirmação. Um exemplo do corpus CRPC é o seguinte:

(17) Na análise do próprio Bloco de Esquerda, parece estar assim, nesta versão da moção de censura, «um indisfarçável desejo de competição que só pode ser com o $\mathrm{PCP}$ », no quadro do chamado jogo parlamentar.

O Sr. Luís Fazenda (BE): Era o que faltava!

A Sr. ${ }^{a}$ Maria Celeste Cardona (CDS-PP): Só pode! (DAR)

A não existência de variação de modo, pessoa e número (aceita-se uma variação limitada em tempo: presente do indicativo e imperfeito do indicativo), a omissão do predicado e a frequência de uso em registos orais parece indicar um processo de lexicalização em curso, que segue um percurso de discursivização (Mendes, 2013) em que advérbio e verbo semiauxiliar modal são reinterpretados como marcador discursivo. 


\section{Dever}

Com o verbo dever, a leitura deôntica é um pouco mais frequente do que a leitura epistémica, ao contrário do que acontecia com o verbo poder (cf. Tabela 2). Nas duas leituras, são dominantes os contextos em que o foco do advérbio não é o predicado.

\begin{tabular}{|c|c|c|c|c|c|c|}
\hline \multicolumn{7}{|l|}{ dever } \\
\hline \multicolumn{3}{|l|}{ valor modal } & \multicolumn{4}{|l|}{ foco } \\
\hline & freq & $\%$ & $\begin{array}{l}\text { foco no } \\
\text { predicado }\end{array}$ & & $\begin{array}{l}\text { foco num } \\
\text { constituinte }\end{array}$ & \\
\hline & & & freq & $\%$ & freq & $\%$ \\
\hline epistémico & 42 & $42 \%$ & 1 & $2 \%$ & 41 & $98 \%$ \\
\hline deôntico & 58 & $58 \%$ & 4 & $7 \%$ & 54 & $93 \%$ \\
\hline
\end{tabular}

Tabela 2: Verbo dever: valores modais e natureza do foco

No valor modal epistémico, o constituinte que constitui o foco é um adjunto temporal em 33 contextos (no total de 41 com foco num constituinte). Note-se ainda que, com esta leitura modal, 36 ocorrências do verbo estão no futuro (36 em 42). As frases (18) ilustram estas duas propriedades:

(18) a. O plantel do Estrela da Amadora só deverá poder voltar a contar com o guardião Tiago durante a próxima semana (...). (J33072)

b. A descriminalização do consumo de droga só deverá voltar a Belém em Outubro ou mesmo Novembro. (J35288)

No valor deôntico, os contextos caracterizam-se pelo presente do indicativo (32/58) ou modo condicional (12/58) do verbo dever. Há uma grande variedade de constituintes que constituem o foco do advérbio, sobressaindo igualmente os adjuntos temporais (14/58) (cf. (19a)), embora em menor proporção e o sujeito (6/58) (cf. (19b)).

(19) a. "A postura e a cortesia serão guardadas a todo o instante e só se deve dizer obrigado quando tal for oportuno". (J27823)

b. E “a primeira regra é que só devem fazer recuperação de listas fora do horário normal os hospitais que têm um grande desempenho", recomenda, exemplificando com o caso da Andaluzia, onde as equipas das unidades de saúde que não têm listas de espera vão ajudar as outras a combater o problema. (J109023)

Os contextos epistémicos de dever na amostragem não apresentam um valor de necessidade, contrariamente ao observado em relação a contextos como (7) com poder. É 
verdade que com o verbo poder o valor de necessidade surgia em contextos com foco do advérbio no predicado, o que nunca ocorre nos dados analisados com o verbo dever. Se observarmos as frases construídas em (20) e (21), vemos que em (21) expressam um evento provável sem que o significado seja equivalente a uma necessidade, contrariamente às frases equivalentes com poder (cf. (20)).

(20) a. Isso só pode ter sido um acidente.

b. Ele só pode ter ido à praia.

(21) a. Isso só deve ter sido um acidente.

b. Ele só deve ter ido à praia.

Os exemplos (21) apenas referem o que é provável que tenha acontecido. A leitura de necessidade não está disponível devido à diferença entre possibilidade e probabilidade. Enquanto a leitura de possibilidade em (7) e em (20) isola uma alternativa de entre um conjunto de possibilidades e afeta o valor de verdade dessas alternativas, a leitura de probabilidade ordena-as do ponto de vista da sua probabilidade, naquilo que é um uso escalar do advérbio só, sem estabelecer uma das alternativas como sendo a única verdadeira.

Note-se que em (21) o advérbio tem valor mirativo, pois a alternativa considerada mais provável é também identificada como mais fraca do que o esperado. Note-se que a frase (21a) pode ser por isso mesmo considerada pragmaticamente estranha pois um acidente não é tipicamente uma alternativa mais fraca do que o esperado.

Também no caso da leitura deôntica de dever os valores pragmáticos tendem a surgir nos poucos contextos em que o foco do advérbio é o predicado. Nesses contextos, a construção com advérbio focalizador exclusivo parece ter valor enfático, como no exemplo (22). Nesta frase, não são verdadeiramente tidas em conta alternativas a partir da qual seria seleccionada uma única (continuar a combatê-los); pelo contrário, o advérbio, ao criar uma leitura de pluralidade de situações, visa reforçar a alternativa apresentada. Note-se que a mesma construção sem advérbio só (e, por isso, devemos continuar a combatê-los) altera essencialmente o grau de força da obrigação. Em certos contextos, como no caso da frase (23), a leitura deôntica tem ainda valor mirativo, no sentido em que a alternativa apresentada é mais fraca do que o desejado ou esperado.

(22) Sabemos bem o que pretendem e, por isso, só devemos continuar, como temos feito até hoje, a combatê-los, recobrando agora as nossas forças e utilizando todos os meios ao nosso alcance. (DAR) 
O homem não resolve os seus próprios problemas: só deve rogar aos deuses que lhos resolvam e se apiadam dele, pois tudo depende de sua vontade impenetrável. (L0897)

\section{Ter de}

Com o verbo ter (de), apenas ocorre no corpus analisado a leitura deôntica (cf. Tabela 3), que tem com ter de valor de obrigação forte e com dever valor de obrigação fraca.

\begin{tabular}{|c|c|c|c|c|c|c|}
\hline \multicolumn{3}{|l|}{ valor modal } & \multicolumn{4}{|l|}{ foco } \\
\hline & freq & $\%$ & $\begin{array}{l}\text { foco no } \\
\text { predicado }\end{array}$ & & $\begin{array}{l}\text { foco num } \\
\text { constituinte }\end{array}$ & \\
\hline & & & freq & $\%$ & freq & $\%$ \\
\hline deôntico & 100 & $100 \%$ & 54 & $54 \%$ & 46 & $46 \%$ \\
\hline
\end{tabular}

Tabela 3: Verbo ter (de): valores modais e natureza do foco

Ocorrem 54 contextos com foco no predicado; nos restantes, o foco do advérbio é o objeto direto (14/46), o adjunto temporal (13/46), o objeto preposicionado (6/46) (cf. (24a)), o sujeito (4/46), uma oração condicional (4/46) ou um numeral (3/46) (cf. (24b)).

(24) a. Em matéria de concertação social, o Sr. Ministro só tem de se queixar do seu Governo, não tem de se queixar de mais ninguém (...). (DAR)

b. Um problema suplementar para Fernando Santos, que só não terá de prescindir de dois deles nas provas da UEFA. (J30969)

Contrariamente ao que verificámos com o verbo dever, mesmo na leitura deôntica, existe com ter de um predomínio de construções em que o foco do advérbio exclusivo é o predicado no seu todo. Em todos esses casos, não existe verdadeiramente uma interpretação contrastiva, tal como se observou já em relação a contextos deônticos com dever no exemplo (22), e os contextos têm associados valores pragmáticos mirativo ou enfático. Estas interpretações prendem-se com o facto de ter de expressar obrigação forte, isto é, de restringir o conjunto de alternativas àquela que é apresentada. $\mathrm{O}$ uso do advérbio focalizador exclusivo envolve por conseguinte valores que diminuem ou fortalecem esse grau modal.

Em contextos como (25), o advérbio exclusivo não identifica uma alternativa de um conjunto de situações possíveis, mas marca antes a situação que é expressa como mais fraca do que o esperado.

(25) a. Para participar só tem de contactar a organização através dos telefones $96 \ldots$ ou $91 \ldots$ (J52552) 
b. Aos 29 anos Neveu, actual campeão francês, fez a diferença no percurso de ciclismo, altamente selectivo, e nos $30 \mathrm{~km}$ de corrida só teve de gerir a vantagem conquistada. (J85762)

c. Eu ensaiava muitas vezes esse tipo de lances. Só tinha de pedir ao Figueiredo para se pôr ao pé do guarda-redes, funcionando como ponto de referência, para lhe cortar a bola junto à cabeça. (noCOD_1031367)

Note-se que a situação não é avaliada necessariamente como a única alternativa, como seria de esperar do uso do advérbio exclusivo. Assim, em (25b), gerir a vantagem conquistada não é a única alternativa para ganhar a corrida (o ciclista poderia ter optado por aumentar a vantagem), mas é a alternativa mais fácil e em (25c) outros lances seriam possíveis mas aquele que é identificado na frase é avaliado como o mais fácil.

Com ter de, o contexto pode também enfatizar a alternativa identificada na frase, ao mesmo tempo que indica que esta não é verdadeiramente sentida como uma obrigação que se impõe ao falante, mas antes como uma consequência natural das circunstâncias. Nas frases (26), a ausência do advérbio produziria uma interpretação de obrigação forte que seria pragmaticamente menos adequada à situação (veja-se, por exemplo: quando se fala do Deputado Luís Beiroco, temos de agradecer a sua contribuição...).

(26) a. A Câmara só tem de aplaudir o proposto neste artigo. (DAR)

b. Quando se fala do Deputado Luís Beiroco, só temos de agradecer a sua contribuição para o trabalho do nosso grupo parlamentar, a contribuição notável que ele deu à discussão do Regimento nesta Câmara... (DAR)

Essa leitura de consequência natural que se impõe pode, aliás, vir contra as expectativas dos envolvidos, como na interpretação de (27), em que felicitar e saudar são atitudes inesperadas mas inevitáveis dadas as circunstâncias.

(27) a. Porém, creio que não foi isso que ouvi, ainda não há muito tempo. Pode ser confusão minha... Vozes do PSD: - Não é, não! O Orador: - Mas, se, efectivamente, é, só tenho de o felicitar porque o PRD só demonstra com isso que é um partido dos nossos dias. (DAR)

b. De facto, há a história do fascismo, de que o Sr. Deputado falou, há a história posterior e há ainda uma história de perigo totalitário, que se lhe seguiu. Só temos de saudar a disponibilidade do PCP para discutir democraticamente estas questões. (DAR) 


\section{Ser capaz de}

A construção com advérbio exclusivo e ser capaz de ocorre apenas na nossa amostragem com leitura de capacidade interna ao participante, como apontam os dados da Tabela 4.

\begin{tabular}{|l|l|l|l|l|l|l|}
\hline \multicolumn{9}{|l|}{ ser capaz de } \\
\hline
\end{tabular}

Tabela 4: Ser capaz de: valores modais e natureza do foco

Tal como com dever, na quase totalidade dos contextos o foco do advérbio recai sobre um dos constituintes com função de sujeito, complemento ou adjunto. Relativamente aos verbos modais até aqui considerados, sobressai com ser capaz de a elevada frequência de contextos em que o foco do advérbio é o sujeito (freq. 65), como se ilustra em (28a,b). São poucos os contextos com foco sobre o predicado (cf. (28c)).

(28) a. Convenceu -se de que só o vento seria capaz de o limpar daquela sujidade invisível (...) (L0935)

b. Ultrapassava-os a todos, o acontecimento. Só Dona Beatriz seria capaz de explicar, mas ficava calada, mesmo com Georgina . (L0701)

c. Quando este reconhece a bondade de algo, por que é que não se há-de louvar? Só se é capaz de criticar? (DAR)

A expressão ser capaz de pode ter uma leitura epistémica, como se ilustra na frase construída (29a), mas essa leitura não é natural com o advérbio exclusivo (cf. (29b)), pelo que só a leitura de capacidade interna está disponível em (30a). Repare-se que a leitura epistémica é natural quando o advérbio ocorre junto do seu foco (30b).

(29) a. É capaz de chover.

b. \# Só é capaz de chover.

(30) a. Ele só é capaz de chegar amanhã. (capacidade)

b. Ele é capaz de chegar só amanhã. (epistémica)

\section{Considerações finais}

A nossa análise focou os verbos semi-modais poder, dever, ter de e a expressão predicativa ser capaz de na sua interação com o advérbio focalizador exclusivo só, cujo foco 
constitui um constituinte proeminente do ponto de vista da estrutura informacional da frase. Os contextos analisados, extraídos do Corpus de Referência do Português Contemporâneo, evidenciam efeitos semânticos e pragmáticos para os quais concorrem diversos fatores, como os conceitos de possibilidade e de necessidade, o tipo de constituinte focalizado pelo advérbio exclusivo, o tipo aspetual do predicado e o tempo verbal. O verbo poder, o mais rico em leituras modais, apresenta também um leque variado de interpretações em contexto com o advérbio exclusivo. Na modalidade epistémica de poder, a restrição operada pelo advérbio sobre as alternativas possíveis produz uma leitura de necessidade em contextos com foco do advérbio no predicado, leitura que ocorre tipicamente em contextos com verbos estativos no tempo passado. Podem ocorrer nos contextos com só e poder/dever/ter de efeitos pragmáticos: um valor de intensificação quando a leitura contrastiva serve para enfatizar a situação representada e um valor mirativo quando a alternativa é considerada mais fraca do que o esperado. A interação da modalidade e do foco pode ainda restringir a ambiguidade de interpretação modal de certos contextos, limitando, por exemplo, a interpretação epistémica da expressão predicativa ser capaz de. A análise dos contextos com o advérbio exclusivo revelou padrões gramaticais associados à interpretação dos verbos modais: o verbo dever tem leitura epistémica no tempo futuro e leitura deôntica no presente e no condicional

Pretende-se analisar no futuro o papel desempenhado pelo advérbio exclusivo e por propriedades aspetuais, temporais e informacionais dos contextos com base numa amostragem do corpus mais extensa, que inclua igualmente dados de corpora de fala.

\section{Referências bibliográficas}

ALONI, Maria; BEAVER, David; CLARK, Brady. "Focus and Topic Sensitive Operators". In: DEKKER, Paul (ed.), Proceedings of the Twelfth Amsterdam Colloquium, ILLC, University of Amsterdam, Amsterdam, The Netherlands, 1999.

ÁVILA, Luciana. Modalidade em perspectiva: estudo baseado em corpus oral do português brasileiro. 253f. Dissertação (Doutoramento em Linguística), Universidade Federal de Minas Gerais, Belo Horizonte, 2014.

ÁVILA, Luciana; MENDES, Amália; HENDRICKX, Iris Ávila, Luciana Beatriz, Amália Mendes, Iris Hendrickx. "Towards a Unified Approach to Modality Annotation in Portuguese". In: Proceedings of the IWCS Workshop on Models for Modality Annotation, MOMA 2015, 14 April, 2015, Queen Mary University of London London, UK, Association for Computational Linguistics, pp. 1-8, 2015. 
BEAVER, David; CLARK, Brady Z. Sense and Sensitivity. How Focus Determines Meaning. Oxford: Wyley-Blackwell, 2008.

BYBEE Joan L.; PERKINS, Revere; PAGLIUCA, William. The evolution of grammar: Tense, aspect and modality in the languages of the world. Chicago: University of Chicago Press, 1994.

DRYER, Matthew S. "The pragmatics of association with only". Paper presented at the 1994 Winter Meeting of the L.S.A. Boston, Massachussets, USA, 1994.

DUARTE, Maria Eugênia “A expressão da modalidade deôntica e epistêmica na fala e na escrita e o padrão SV". Revista do GELNE (UFC) 14, p. 77-94, 2012.

GENÉREUX, Michel ; HENDRICKX, Iris ; MENDES, Amália. "Introducing the Reference Corpus of Contemporary Portuguese On-Line". In: Proceedings of the Eighth International Conference on Language Resources and Evaluation - LREC 2012, Istanbul, May 21-27 2012, pp. 2237-2244, 2012.

HENDRICKX, Iris; MENDES, Amália; MENCARELLI, Silvia. "Modality in Text: a Proposal for Corpus Annotation". In: Proceedings of the Eighth International Conference on Language Resources and Evaluation - LREC 2012, Istanbul, May 21-27 2012, pp. 18051812, 2012a.

HENDRICKX, Iris; MENDES, Amália; MENCARELLI, Silvia; SALGUEIRO, Agostinho. Modality Annotation Manual, version 1.0. Centro de Linguística da Universidade de Lisboa, Lisboa, Portugal, 2012b.

HOYE, Leo. Adverbs and Modality in English. London: Longman, 1997.

KRIFKA, Manfred. "Focus and the Interpretation of Generic Sentences". In: CARLSON, Gregory N.; PELLETIER, Francis Jeffry (eds) The Generic Book. Chicago: The University of Chicago Press, pp. 238-264, 1995.

LYONS, John. Semantics, Vol. 2. Cambridge: Cambridge University Press, 1977.

MENDES, Amália. "Processos de gramaticalização". In: RAPOSO, Eduardo B. P.; BACELAR DO NASCIMENTO, Maria Fernanda; COELHO da MOTA, Maria Antónia; SEGURA, Luísa; MENDES, Amália (orgs.) Gramática do Português, vol. I. Lisboa: Fundação Calouste Gulbenkian, pp. 249-293, 2013.

MENDES, Amália; HENDRICKX, Iris; SALGUEIRO, Agostinho; ÁVILA, Luciana "Annotating the Interaction between Modality and Focus: the case of exclusive particles". In: Proceedings of the 7th Linguistic Annotation Workshop \& Interoperability with Discourse (LAW VII). Association for Computational Linguistics, Sofia, Bulgaria, August 8-9 2013, pp. 228-237, 2013. 
MORANTE, Roser; SPORLEDER, Caroline. "Modality and Negation: An Introduction to the Special Issue", Computational Linguistics, 38(2), pp. 223-260, 2012.

MOREIRA, Benjamim. Estudo de alguns marcadores enunciativos do português. Dissertação de Doutoramento, Universidade de Santiago de Compostela, Faculdade de Filologia, Santiago de Compostela, Espanha, 2005.

OLIVEIRA, Fátima. Para uma semántica e pragmática de DEVER e PODER. Dissertação de Doutoramento, Universidade do Porto, Porto, Portugal, 1988.

OLIVEIRA, Fátima. Questões sobre Modalidade em Português. Cadernos de Semântica n $^{\circ}$ 15, Lisboa: FLUL, 1993.

OLIVEIRA, Fátima; MENDES, Amália. "Modalidade". In: RAPOSO, Eduardo B. P.; BACELAR DO NASCIMENTO, Maria Fernanda; COELHO da MOTA, Maria Antónia; SEGURA, Luísa; MENDES, Amália (orgs.) Gramática do Português, vol. I. Lisboa: Fundação Calouste Gulbenkian, pp. 623-669, 2013.

PALMER, Frank R. Mood and Modality. Cambridge: Cambridge textbooks in linguistics, 1986.

PORTNER, Paul. Modality. Oxford: Oxford University Press, 2009.

RAPOSO, Eduardo Buzaglo Paiva. “Advérbio e sintagma adverbial” ". In: RAPOSO, Eduardo B. P.; BACELAR DO NASCIMENTO, Maria Fernanda; COELHO da MOTA, Maria Antónia; SEGURA, Luísa; MENDES, Amália (orgs.) Gramática do Português, vol. I. Lisboa: Fundação Calouste Gulbenkian, pp. 1569-1684, 2013.

ROOTH, Mats. "A theory of focus interpretation". Natural Language Semantics 1, pp. 75116, 1992.

VAN der AUWERA, Johan; PLUNGIAN, Vladimir A. "Modality's semantic map". Linguistic Typology 2(1), pp. 79-124, 1998.

Von FINTEL, Kai-Uwe. Restriction on Quantifier Domains. UMass Amherst dissertation, Amherst, Massachussets, USA, 1994.

\section{Fonte dos exemplos}

Corpus de Referência do Português Contemporâneo

L0979 - GONÇALVES, Raquel. Elementos Alquímicos. Lisboa: Colibri, 1995.

L0935 - BERTO, Al. Lunário. Contexto, 1988.

L0701 - NAVARRO, Modesto. Seis Mulheres na Madrugada. Lisboa: Caminho, 1995.

J99704 - Jornal Público, 2 março 2003.

J35288 - Jornal Público, 27 de julho de 2000 
J52552 - Jornal Público, 2 de setembro de 2000

J85762 - Jornal Público, 25 de setembro de 2002

noCOD_1062920 - Jornal Público, 30 de abril de 2004

noCOD_1062203 - Jornal Público, 21 de Setembro de 2004

J109023 - Jornal Público, 20 de fevereiro de 2004

J69887 - Jornal Diário de Notícias, 29 de maio de 1996

J9736 - Jornal A Capital, 14 de novembro de 1995

J44918 - Jornal Expresso, 23 de agosto de 1997

J47486 - Jornal Expresso, 21 de fevereiro de 1998

J33072 - Jornal O Jogo, 5 de agosto de 2000

J27823 - Jornal O Jogo, 27 de junho de 2000

J30969 - Jornal O Jogo, 24 de julho de 2000

noCOD_1031367 - Jornal A Bola, s/d

R1641 - Revista Máxima nº5, fevereiro de 1994

DAR: Diário da Assembleia da República. 